\title{
PLAYING WITH THE PAST: DIGITAL GAMES AND THE SIMULATION OF HISTORY
}

\author{
José Manuel Leiva Aldea \\ (Universidad de Málaga, España) \\ joseleivaaldea@uma.es
}

Recibido el 06 de septiembre de 2017; aceptado el 20 de noviembre de 2017

Cada vez son más las publicaciones que, a nivel académico, están abordando la cuestión de los videojuegos. Y es que el sector del videojuego no siempre ha contado con este respaldo por parte del ámbito científico, a pesar de ser la principal industria audiovisual y de entretenimiento en lo que llevamos del s. XXI, superando en ingresos a la del cine y la música. En la introducción de Playing with the Past: Digital Games and the Simulation of Historyı se habla de por qué se eligió dicho título, que incluye la palabra "jugar", término que pretende aludir a una nueva forma de acercarse a la historia, de una manera alternativa a las investigaciones académicas convencionales.

Este volumen se divide en cinco partes: History as a Process (La Historia como un proceso), History Written by the West (La Historia escrita por Occidente), User-Generated History (Historia generada por el usuario), The Politics of Representation (Políticas de representación) y Looking Back on the End of the World (Mirando atrás hacia el fin del Mundo).

Como bien indica su título, el primer bloque del libro explica cómo el fenómeno histórico es un complejo en lugar de una sucesión de hechos puntuales que definen la historia, idea que, según autores como Andrew Justin Miller, Daniel Reyonlds o Adam Chapman, entre otros, se potencia en los videojuegos. Es decir, que la historia la conforman una serie de decisiones por parte de sus actores con sus respectivas consecuencias. Estos factores se integrarían dentro del proceso histórico a modo de "narrativa". En esto tendrá una gran importancia el videojuego, ya que en ellos será habitual que tomemos decisiones que irán determinando la trama del mismo. Será frecuente que estas decisiones afecten al transcurso de períodos históricos, haciéndonos partícipes del cambio del mismo, por lo que el

\footnotetext{
1 WILHELM, M. y ELLIOT, A., (ed.) y VV.AA. (2013). Playing with the past: digital games and the simulation of History. Bloomsbury Publishing: Londres
} 
espectador/jugador aprendería cómo la construcción de la Historia se debe a una serie de decisiones tomadas por actores en un momento determinado, como se dijo con anterioridad.

El segundo bloque, "Historia escrita por Occidente", aborda el problema de cómo miramos la Historia a través de una perspectiva eurocéntrica u occidental, planteamiento que sigue vigente en determinados videojuegos (se incide en el hecho de que hay algunos que hacen todo lo contrario), sobre todo en aquellos que simulan periodos históricos imperialistas como es la época del Imperio Romano, tratando como “'inferiores"' a las facciones ' bárbaras". La cuestión de América y el denominado "Nuevo Mundo" también es foco de miradas en este bloque. Joshua D. Holdenried y Nicolas Trépanier analizan la perspectiva europeísta, que negaba la identidad cultural de los pueblos indígenas de estos territorios. Otro capítulo se centra en el concepto de conciencia e identidad nacional. El último capítulo de este bloque analiza el fenómeno de los juegos Otome de Japón, en el que chicas jóvenes asumen un rol en el que se tienen que enamorar de un determinado personaje histórico.

Un tercer bloque se centra en lo relativo a la veracidad y realismo en las representaciones históricas en los videojuegos, y cómo el jugador es capaz de reconstruir este pasado, tanto por lo que ve como por lo que ya sabe de antemano. En este apartado, varios autores como Josef Köstlbauer tratarán la cuestión de los videojuegos militares y de cómo en ocasiones se simulan situaciones de guerra que rozan la realidad, mientras que Tom Apperley trata la capacidad del usuario de modificar estos "códigos históricos" a través del mooding2 para alterar la Historia y crear escenarios geo- temporales alejados de cualquier realidad.

"Políticas de la representación" es el cuarto apartado del libro. Trata una serie de aspectos que versan sobre la exactitud de la recreación, algo que suele estar en el punto de mira de los historiadores e historiadores del arte. Douglas N. Dow focaliza su estudio en el análisis de la veracidad y el posible anacronismo en la recreación histórico-artística de la Florencia del Renacimiento en el videojuego Assassin's Creed II. Andrew Wackerfuss, Clemens Reisner y Marcus Schulzke abordarán el período de la Segunda Guerra Mundial y la Guerra Fría, respectivamente, hablando de las posibilidades de recrear la guerra en el aire y de cómo el joven jugador tiene un primer acercamiento a qué fue la Guerra Fría y las consecuencias de ésta en el mundo actual. Además, se incide en el hecho de que, gracias a estos videojuegos, después del primer acercamiento que mencionábamos, el usuario puede interesarse por los distintos 
períodos históricos y animarse a investigar sobre éstos.

Por último, Looking Back on the End of the World hace un análisis de cómo podemos imaginar el futuro de la humanidad en los videojuegos, ya que no siempre se recrea el pasado. Se hará hincapié la manera en la que normalmente estas representaciones suelen tener cierto componente distópico, con un punto de vista que no difiere mucho de la idea que se tenía sobre el futuro en el pasado s. XX. William M. Knoblauch dedica su capítulo al hipotético fin del Mundo, que se pensaba que tendría lugar durante la Guerra Fría. Joseph A. November y Tom Cutterham profundizarán en torno a las visiones postapocalípticas de una América distópica en la popular serie de videojuegos Fallout. En ella, el usuario "viajará" al Estados Unidos de finales del s. XXI, con una estética futurista de los años 50’ del pasado s. XX. Los últimos dos capítulos de este bloque discuten acerca de los riesgos potenciales de las armas biológicas y su representación en juegos bélicos futuristas, en los que la humanidad se enfrenta a su posible extinción.

Con Playing with the Past: Digital Games and the Simulation of History se hace un recorrido por algunas de las numerosas posibilidades que se nos ofrece a historiadores e historiadores del arte para interpretar el pasado, presente y futuro, colaborando en la creación de un corpus científico que legitime, de una vez, el estudio de los videojuegos en el ámbito de las universidades. 